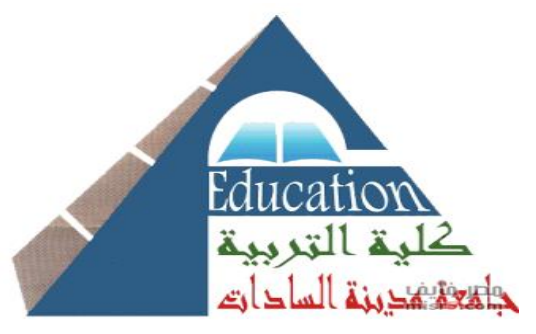

University of Sadat City

Faculty of Education

Dept. of Curriculum\&Instruction

\title{
A Gamification-Based Program to Enhance English Vocabulary Learning and Retention among Kindergartners
}

\author{
A Thesis \\ Submitted for the fulfillment of the requirements for the Master Degree in \\ Education \\ (EFL Curriculum \& Instruction) \\ Prepared by

\section{Randa Abdel Salam Saad Belal}

English language teacher

Supervised by

\section{Dr. Eman Mohammed Abdel Haq \\ Prof. of Curriculum and EFL \\ Instruction and Dean of Faculty \\ of Education \\ Benha University}

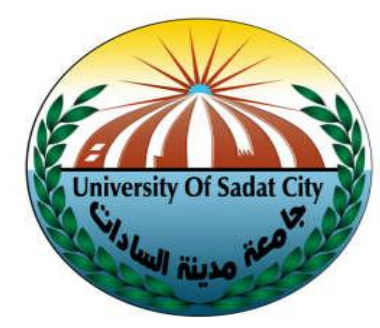

. 


\begin{abstract}
A Gamification-Based Program to Enhance English Vocabulary Learning and Retention among Kindergartners

By

Randa Abdelsalam Saad Belal.

Source

Faculty of Education, Sadat City University

Supervisors
\end{abstract}

Dr. Eman Mohammed Abdel Haq

Prof. of Curriculum and EFL Instruction

and Dean of Faculty of Education

Benha University
Dr. Adel Tawfik Ibrahim

Prof. of Curriculum and Instruction and Former Dean of Faculty of Education

Sadat City University

\title{
Dr. Eman Ali El-Sayed Diyyab \\ Lecturer of Curriculum and EFL Instruction \\ Faculty of Education \\ Sadat City University
}

The current research investigated the effect of using a gamification-based program on enhancing English vocabulary learning and retention among kindergartners. The research participants were 60 kindergartners. They were divided into two main groups: experimental and control. 30 participants of the experimental group were taught using the gamification-based program while the control group participants received regular instruction. The instruments of the research were a checklist of EFL vocabulary learning aspects and sub-aspects and an EFL vocabulary learning test. It also was used as a delayed- post test. Having administering the research instruments, the present research findings revealed that the gamification-based program proved to have a positive effect on enhancing English vocabulary learning and retention among kindergartners.

Key words: Gamification- Vocabulary Learning- Vocabulary Retention- Kindergartners. 


\section{Introduction}

Vocabulary learning is very important for people who learn English as foreign language. Learning vocabulary, according to Tozcu and Coady (2004: 473), is an important component of and foreign language acquisition as well as academic accomplishment, and it is essential to reading comprehension and competency, with which it is strongly associated.

Teaching vocabulary is one of the most important aspects of any language class because it allows foreign language learners to understand and express themselves through language. Learners can express their ideas in written and spoken English by learning vocabulary. They must memorize words when learning vocabulary. They must also understand which part of speech each word belongs to, whether it is a noun, verb, adjective, or adverb. Students who are learning a foreign language must understand the meaning of the words. When students don't understand the meaning of a word, there are a variety of consequences or impacts that can occur. For example, students may misinterpret the message's meaning.

Thus, it can be concluded that one of the most essential aims of teaching English as a foreign language is enhancing EFL vocabulary learning and retention among kindergartners. There have been some difficulties that have obstructed achieving this aim such as the words are hard to pronounce, the students have struggled to choose the appropriate meaning of the terms and were still unsure how to utilize the words in context and the number of words that children must learn is enormous. Hence, in order to overcome such difficulties and enhance EFL vocabulary learning and retention, a gamification-based solution has been suggested and highlighted for its pedagogical depth, flexibility, and applicability.

The trend of incorporating game elements into non-gaming facilities has gotten a lot of attention in recent years. Gamification in education has a significant impact on motivation, user interaction, and social effects. Gamified components such as points, badges, feedbacks, level, awards and challenges have been used. According to Bunchball (2010) and Kapp (2012), Educational gamification is a method of teaching that converts 
learning into a game. Students learn through doing things like working through problems or playing games. This is not to argue that all activities are solely for entertainment. Gamification is a way of teaching vocabulary to kindergartners using game ideas and components.

Moreover, Lui (2014) asserted that gamification has been found to increase the interest and engagement in learning. Because of the positive feedback they receive from the game, students feel more driven to learn. When gamifying a course or even an activity, a clear purpose must be established. A well-designed game can boost kids' motivation, engagement, and cognitive growth. Gamification has been found to improve students' attitudes toward language study and to promote learning when used correctly.

\section{Literature review}

\section{EFL Vocabulary}

Vocabulary is the students' main tool in their attempt to communicate effectively in English. As a result, several researchers have attempted to define it. Hanson and Padua(2011), for example, defined vocabulary as the words we use to communicate in both oral and written language. Vocabulary, according to Beck, McKeown and Kucan(2008), is a collection of words that a person can recognize and deduce meanings from in either written or spoken language. As stated by Jalongo and Sobolak (2010) and Neuman and Dwyer (2009), supporters of this viewpoint believe that vocabulary is separated into two categories: expressive vocabulary and receptive vocabulary. Both expressive and receptive vocabularies start to develop in early childhood, and they continue to develop and grow as a result of life experiences and interactions with others.

\section{Importance of EFL vocabulary}

Vocabulary learning is a crucial element of mastering a foreign language, according to students, teachers, curriculum designers, and researchers alike. Bromley (2002, p.7) 
emphasized the importance of vocabulary in this context by stating four points:

a. Improves comprehension:according to some estimations, word knowledge can help learners attain comprehension by as much as $80 \%$. A large vocabulary is well known for improving students' book experiences and making it easier for them to decode the meaning of odd words they find everywhere.

b. Increases achievement:learners with large vocabularies do better on achievement tests than learners with small vocabularies. Furthermore, having a rich vocabulary assists learners in achieving high standards in school and at work later.

c. Facilitates communication:when learners have wide and complex vocabularies at their command, they are able to convey their thoughts and feelings, as well as understand and communicate with others. As a result, they will be able to communicate more effectively.

d. Shapes thinking:vocabularies are instruments for analyzing, inferring, assessing, and reasoning. As a result, learners who understand and can use the grammatical concepts (verb, noun, adjective, and adverb) can discuss and rewrite their writing in a different way to make it clearer to others.

\section{Challenges in teaching EFL vocabulary}

Research of teachers' beliefs and perspectives on language, as well as reviews of the theoretical aspects of these studies, reveal lots of problems with current practices:

- Narrow views and control of teachers: some teachers have a one-dimensional view of language teaching's goal. Watts (1995) investigated fifth and sixth grade teachers in this regard, finding that they taught language to help their students understand what they were about to learn. They did not understand the benefits of teaching vocabulary in a broader sense, and they did not adjust their teaching methods. 
- Mechanical activities in manuals: several low-level, mechanical vocabulary instruction manuals and content manuals are available. Ryder and Graves (1994) examined fourth and sixth grade basal manuals and presented instructions, claiming that they were neither rich nor deep. It wasn't efficient enough to improve comprehension.

- Flashcard practice and little involvement: although using flashcards can help with sight word recognition, Stahl and Fairbanks (1986) discovered that frequent repeats of the same type of information about targeted words had little effect on comprehension. As a result, relevant and varied experiences are required for students to get a deep understanding of these words.

- Incomplete definitions: dictionary definitions are frequently insufficient to explain new terms in dictionaries. Mckeown (1993) investigated word learning in fifth graders and discovered that dictionaries define words using similar phrases that do not fully convey the concepts that the words represent. She further said that memorizing definitions was ineffective for understanding vocabulary.

\section{Gamification and Its Historical Background}

Nick Pelling coined the term "gamification" in 2002, and the term was first used in 2008. Gamification is defined by Deterding et al. (2011, p.9) as the usage of game design principles in non-game contexts. Gamification is described by Werbach and Hunter (2012, p.16) as "the employment of game components and game-design techniques in non-game contexts." While Nicholson (2012) defined it as the primary use of game layers being to assist participants in developing a deeper connection to the underyling topic rather than to deliver external incentives. Flores (2015, p.38) stated that the goals of gamification are to improve the engagement and motivation of people (called users) through the use of game features and techniques. As a result, this study defines gamification as the use of game elements and mechanics to push users toward the fulfillment of certain goals. 


\section{Benefits of gamification in education}

Lee and Hammer (2011) and Pavlus (2010) reported that:

- Gamification gives an opportunity for hesitant students to speak up, as well as for all students to openly engage in social interaction by speaking, listening, and actively investigating ideas, when they are encountered with a problem.

- It alters the routine of instruction.

- Self-learning gives students control over their learning. Students are allowed to fail and try again without repercussions.

- Gamification isn't just for students in the classroom. Outside of class, students practice in their leisure time and interact with their classmates and teacher.

- Feedback is given to students right away.

- Gamification has a beneficial effect on academic achievement of some subjects such as: languages, mathematics and social studies and music.

\section{Context of the Problem}

Despite the importance of EFL vocabulary learning for EFL students, the researcher noticed a shortage of EFL vocabulary learning aspects among kindergartners while working as an English language teacher. While teaching English, it was obvious that EFL vocabulary learning aspects were not given the attention they deserved and they were totally neglected. It was also noted that the observations above are consistent with past studies concerned with the problem of EFL vocabulary learning and retention such as the studies of Wright and Neuman (2013); Zhou andLi (2017); AlNatour and Hijazi (2018); Kara andEveyik-Aydın (2019); Kelley, Barker, Peters-Sanders, Madsen, Seven, Soto, Olsen and Goldstein (2020); Cedeño and Santos (2021); Henderson, van Rijn, James, Walker, Knowland and Gaskell (2021). 
To document the current research problem, a pilot study was conducted to determine the kindergartners' difficulties with EFL vocabulary learning. The pilot study consisted of an EFL vocabulary test. It was administered to a sample of kindergartners $(\mathrm{N}=30)$ enrolled in second stage of NES kindergarten during the second semester of the 2019/2020 academic year. It was reported that they encountered significant difficulties in EFL vocabulary learning.

\section{Statement of the Problem}

The problem of the present research was lies in the poor performance of EFL kindergartners in vocabulary learning.As a result, the current research attempted to assist kindergartners in enhancing their EFL vocabulary learning and retention.

\section{Questions of the Research}

The current research tried to answer the following questions:

1- What are the EFL vocabulary aspects required for kindergartners?

2- What are the features of the suggested gamification-based program?

3- What is the impact of thesuggested gamification-based program on enhancing English vocabulary learning?

4- What is the impact of thesuggested gamification-based program on enhancing English vocabulary retention?

\section{Hypotheses of the Research}

The present research tested the following hypotheses

1.There is a statistically significant difference at the 0.01 level between the mean scores of the research participants of the experimental and control groups on the post measurement of the overall EFL vocabulary test in favor of the experimental group. Three sub-hypotheses are included in the first hypothesis:

1. A There is a statistically significant difference at the 0.01 level between the mean scores of the research participants of the experimental and control groups in EFL vocabulary recognition on the post measurement of the EFL vocabulary test in favor of the experimental group. 
1. B There is a statistically significant difference at the 0.01 level between the mean scores of the research participants of the experimental and control groups in EFL vocabulary meaning/ comprehension on the post measurement of the EFL vocabulary test in favor of the experimental group.

1. C There is a statistically significant difference at the 0.01 level between the mean scores of the research participants of the experimental and control groups in EFL vocabulary use on the post measurement of the EFL vocabulary test in favor of the experimental group.

2. There is not a statistically significant difference at the 0.01 level between the mean scores of the experimental group on the post/delayed-post measurement of the EFL vocabulary test.

\section{Aims of the Research}

This research aimed at:

1- Identifying some English vocabulary learning aspects which kindergartners should acquire.

2- Determining the most important gamification activities which can contribute to kindergartners' learning of English vocabulary.

3- Investigating the effectiveness of gamification on kindergartners' acquisition of English vocabulary.

\section{Significance of the Research}

The present research may be beneficial in:

1- Identifying a list of the most important English vocabulary learning aspects for kindergartners.

2- Identifying the nature of gamification that can contribute to simplify and facilitate the kindergartners' English vocabulary learning. 
3- Attracting the attention of English teachers of kindergarten stage and directing them to the use of gamification in education in general and to its use in English vocabulary learning and retention in particular.

\section{Delimitations of the Research}

1- Sixty kindergartners at Nile Egyptian Schools, Sadat City Branch participated in the research.

2- Some EFL vocabulary aspects required for kindergartners such as (recognition, meaning/ comprehension and use).

3- The second semester of the academic year 2019/2020.

\section{Instruments and Materials of the Research}

The following instruments and materials were prepared and used by the researcher:

1. A checklist of EFL vocabulary learning aspects and sub- aspects.

2. An EFL vocabulary learning test.

3. A gamification-based program.

4. A teacher's guide.

\section{Participants of the Research}

The participants of the present research included60 kindergartners. They were chosen randomly from amongst Nile Egyptian Schools, Sadat City Branch kindergartners during the second semester of the 2019/2020 academic year.Their ages ranged from 5-6 years old. They all live in Sadat City in Menufiya Governorate. These students were randomly assigned to an experimental group $(\mathrm{N}=30)$ and a control group $(\mathrm{N}=30)$.

\section{Design of the Experiment}

The two-group pre-post-assessment design was used in the experiment. The participants were assigned randomly to an experimental group and a control group. The experimental group kindergartners were taught using the gamification-based program while the control group kindergartners received regular instruction. 


\section{Definition of terms}

\section{English Vocabulary Learning}

In the current research, EFL vocabulary learning is operationally defined as , kindergartners' performance in acquiring new words represented in recognizing, understanding the meaning and using these words correctly.

\section{English Vocabulary Retention}

Ramezanali (2017) mentioned that the ability to remember the meaning of a new word after a certain amount of time is known as retention. Word retention can be divided into two categories: short-term and long-term.

The researcher adopted Ramezanali's definition operationally as it is relevant to the research aims.

\section{Gamification}

Kim, Song, Lockee and Burton (2018:29) defined gamification as a set of actions and methods for applying and using game mechanics to solve problems in learning and education.

The researcher adopted Kim et al.'s definition operationally as it is suitable for the research aims.

\section{Procedures}

\section{Instruments and Materials of the Research}

To achieve the objectives of research, the researcher constructed the following instruments:

1. A checklist of EFL vocabulary learning aspects and sub- aspects.

2. An EFL vocabulary learning test.

3. A gamification-based program.

4. A teacher's guide.

\section{The checklist of EFL Vocabulary Learning Aspects and Sub-aspects}


The researcher designed an EFL vocabulary learning aspects checklist to determine the most important vocabulary learning aspects and sub-aspects appropriate for kindergartners. Thechecklist in its initial form consisted of 12 points.

\section{Validity}

The EFL vocabulary learning checklist in its initial form was submitted to a panel of TEFL jury members $(\mathrm{N}=9)$ to ensure its validity. They were kindly requested to check $(\checkmark)$ at the appropriate option beside each sub-aspect, determine whether the EFL vocabulary learning aspects and sub-aspects are appropriate or not for the subjects of the research and modify any point when necessary.

The EFL jury members suggested the following modifications: organizing the checklist points into aspects and sub-aspects, rephrasing all the verbs of aspects from infinitive to gerund and omitting some unnecessary points. Taking the jury members' suggestions into consideration, the final checklist of EFL vocabulary learning aspects and sub- aspects was modified. The checklist in its final form consisted of three aspects and eight sub-aspects.

\section{The EFL Vocabulary Learning Test}

The EFL vocabulary learning test was prepared by the researcher to measure some kindergartners' vocabulary learning aspects and sub-aspects which are: 1. Recognition (a. Recognizing the letter sound association, b. Pronouncing the words correctly and c. Organizing the learned words in meaningful groups), 2. Meaning $\backslash$ Comprehension (a. Understanding the meaning of the words, b. Analyzing the word parts and c. Sketching the words) and 3. Use ( a. Using appropriate vocabulary for his/her grade and b. Writing the words correctly).

\section{Description of the EFL Vocabulary Learning Test}

The EFL vocabulary learning test was used at first, as a pre-test. Then, it was used as a post-test in order to investigate the effect of the gamification-based program in enhancing EFL vocabulary learning. After that, it was used one more time after to investigate the effect of the gamification-based program in EFL vocabulary retention. 
It consisted of three parts. These parts were developed to measure some EFL vocabulary learning aspects (recognition, meaning \comprehension, and use).

Table (1): Specification of the EFL Vocabulary Learning Test

\begin{tabular}{|c|c|c|c|}
\hline Part & Questions & Measured aspect & Mark \\
\hline \multirow{2}{*}{ One } & A (1-5) & & \\
& B (1-5) & Recognition & 15 \\
C (1-5) & A (1-5) & Meaning \ & 15 \\
\hline Two & B (1-5) & Comprehension & \\
& C (1-5) & & 10 \\
\hline Three & A (1-5) & U (1-5) & 40 \\
\hline Total & & & \\
\hline
\end{tabular}

\section{Validity of the Test}

To ensure the validity of the EFL Vocabulary Learning Test, the researcher submitted it in its initial form to a jury of TEFL experts and specialties. They were kindly requested to judge the test face validity in terms of clarity of the test instructions, suitability of the test items for assessing the content of the program and appropriateness of the test items for the research participants. Some modifications were made in the test in the light of the jury members' comments

\section{Internal Consistency Validity of the Test}

Internal Consistency Validity of the Test was determined through calculating the value of the correlation between the scores of each of the test items separately and the test 
as a whole, using the Spearman Brown equation to calculate the correlation coefficient, and the results are shown in the following table:

Table (2): The values of the Correlation Validity Coefficient for the EFL Vocabulary Learning Test items

\begin{tabular}{|c|c|c|c|c|c|}
\hline \multicolumn{6}{|c|}{ Recognition } \\
\hline Item & $\begin{array}{l}\text { Test correlation } \\
\text { coefficient }\end{array}$ & Item & $\begin{array}{l}\text { Test correlation } \\
\text { coefficient }\end{array}$ & Item & $\begin{array}{l}\text { Test correlation } \\
\text { coefficient }\end{array}$ \\
\hline 1 & $0.68 * *$ & 6 & $0.71 * *$ & 11 & $0.86 * *$ \\
\hline 2 & $0.71 * *$ & 7 & $0.64 * *$ & 12 & $0.82 * *$ \\
\hline 3 & $0.69 * *$ & 8 & $0.69 * *$ & 13 & $0.66 * *$ \\
\hline 4 & $0.52 * *$ & 9 & $0.79 * *$ & 14 & $0.73 * *$ \\
\hline 5 & $0.84 * *$ & 10 & $0.83 * *$ & 15 & $0.89 * *$ \\
\hline \multicolumn{6}{|c|}{ Meaning /Comprehension } \\
\hline 16 & $0.79 * *$ & 21 & $0.55 * *$ & 26 & $0.75 * *$ \\
\hline 17 & $0.84 * *$ & 22 & $0.83 * *$ & 27 & $0.71 * *$ \\
\hline 18 & $0.60 * *$ & 23 & $0.69 * *$ & 28 & $0.80 * *$ \\
\hline 19 & $0.62 * *$ & 24 & $0.77 * *$ & 29 & $0.63 * *$ \\
\hline 20 & $0.78 * *$ & 25 & $0.91 * *$ & 30 & $0.74 * *$ \\
\hline \multicolumn{6}{|c|}{ Use } \\
\hline 31 & $0.76 * *$ & 35 & $0.59 * *$ & 39 & $0.68 * *$ \\
\hline 32 & $0.66 * *$ & 36 & $0.83 * *$ & 40 & $0.62 * *$ \\
\hline 33 & $0.80 * *$ & 37 & $0.76^{* *}$ & & \\
\hline 34 & $0.78 * *$ & 38 & $0.80 * *$ & & \\
\hline
\end{tabular}

** Significant at $(0.01)$

As illustrated in the previous table, all the test items are related to the test as a whole at the level (0.01), which indicates that the test has a high degree of validity of internal consistency which means that all the test items were in the same context to achieve the main aim of the test.

\section{Reliability of the test}

To calculate the value of the reliability factor for the test, the calculation of the value of the coefficient of Cronbach's Alpha and Guttman Split-Half Coefficient were calculated through using the Statistical Package for Social Sciences (SPSS) program, version 22 and the results were shown in the following table: 
Table (3): The Reliability of The EFL Vocabulary Learning Test

\begin{tabular}{ccccc}
\hline $\begin{array}{c}\text { No. of test } \\
\text { items }\end{array}$ & Sample & $\begin{array}{c}\text { Cronbach's Alpha } \\
\text { value }\end{array}$ & $\begin{array}{c}\text { Guttman Split-Half } \\
\text { Coefficient value }\end{array}$ & Sig. \\
40 & 20 & 0.791 & 0.815 & High \\
\hline
\end{tabular}

Accordingly, the previous value of Cronbach's Alpha Coefficient is 0.791 and the value of Guttman Split-Half Coefficient is 0.815 which indicates that the test was highly reliable.

\section{Administering the EFL Vocabulary Learning Test}

The EFL vocabulary learning test was administered to the two groups of the study. The pre-testing took place on 25/05/2020 in the second semester of the academic year 2019/2020 while the post-testing took place on 25/06/2020.

\section{The Gamification-Based Program}

The program consisted of 10 sessions. After the pre-testing, the program begins with an introduction and orientation of the program to the research participants. The researcher categorized the remained instructional sessions into three categories which were (recognition, meaning/ comprehension and use).Then, there was a general review on all sessions. After that, there was a post-testing after finishing the program. All these ten sessions contain details about each EFL vocabulary learning aspect and sub-aspect found in the checklist. These sessions together form the gamification-based program. Finally, there was a delayed post-testing after two weeks.

\section{Teacher's Guide}

The teacher's guide included the aims and objectives of the program, the teaching strategies that can be used during the sessions and also the correct answers of activities. 


\section{Data Analysis}

\section{Homogeneity of research groups in the pre-administration of the test}

The research instrument was applied prior to the experiment to the research participants in order to ensure their homogeneity and to adjust the experimental variable.

With regard to the pre-administration of the EFL vocabulary learning test on the two groups (Experimental/Control), the test was pre-administered to the two research groups on 25/05/2020, and t-test was used to identify the significance of the difference between the mean scores of the two groups.

Table (4): The t-value and Level of Significance in the Pre-administration (Experimental/Control) of the EFL Vocabulary Learning Test

\begin{tabular}{|c|c|c|c|c|c|c|c|c|c|}
\hline Levels & Group & No & Mean & S. D & D. F & F. Value & Sig. & t-value & Level of sig. \\
\hline \multirow[b]{2}{*}{ Recognition } & Control & 30 & 10.03 & 1.82 & \multirow[b]{2}{*}{58} & \multirow[b]{2}{*}{0.34} & \multirow{2}{*}{$\begin{array}{l}\text { Not } \\
\text { sig. }\end{array}$} & \multirow[b]{2}{*}{0.99} & \multirow{2}{*}{$\begin{array}{c}\text { Not. Sig. } \\
\text { at } 0.01 \\
\text { level }\end{array}$} \\
\hline & Experimental & 30 & 10.5 & 1.79 & & & & & \\
\hline \multirow{2}{*}{$\begin{array}{l}\text { Meaning/ } \\
\text { Comprehension }\end{array}$} & Control & 30 & 9.6 & 1.75 & \multirow{2}{*}{58} & \multirow{2}{*}{2.88} & \multirow{2}{*}{$\begin{array}{l}\text { Not } \\
\text { sig. }\end{array}$} & \multirow{2}{*}{0.18} & \multirow{2}{*}{$\begin{array}{c}\text { Not. Sig. } \\
\text { at } 0.01 \\
\text { level }\end{array}$} \\
\hline & Experimental & 30 & 9.5 & 2.35 & & & & & \\
\hline \multirow{2}{*}{ Use } & Control & 30 & 2.46 & 1.67 & \multirow{2}{*}{58} & \multirow{2}{*}{0.38} & \multirow{2}{*}{$\begin{array}{l}\text { Not } \\
\text { sig. }\end{array}$} & \multirow{2}{*}{0.88} & \multirow{2}{*}{$\begin{array}{c}\text { Not. Sig. } \\
\text { at } 0.01 \\
\text { level }\end{array}$} \\
\hline & Experimental & 30 & 2.86 & 1.83 & & & & & \\
\hline \multirow{2}{*}{ Overall Test } & Control & 30 & 22.1 & 3.73 & \multirow{2}{*}{58} & \multirow{2}{*}{2.19} & \multirow{2}{*}{$\begin{array}{l}\text { Not } \\
\text { sig. }\end{array}$} & \multirow{2}{*}{0.71} & \multirow{2}{*}{$\begin{array}{c}\text { Not. Sig. } \\
\text { at } 0.01 \\
\text { level }\end{array}$} \\
\hline & Experimental & 30 & 22.86 & 4.56 & & & & & \\
\hline
\end{tabular}

* The tabular value of t-test at the level of (0.01) and $58 \mathrm{D}$.F is (2.02).

From the previous table, it can be clarified that the two groups were independent and homogeneous. The homogeneity of the two groups was illustrated using the value and significance of the coefficient $(\mathrm{F})$ in the previous table, and the absence of a statistically significant difference at the level of $(0.01)$ between the mean scores of the research participants, the experimental and control research groups, in the pre-administration of the EFL vocabulary learning test. 


\section{Findings and Discussion}

The researcher provided the results of the research after applying the research procedures. For this aim, the researcher answered the research questions, verified their hypotheses, discussed and interpreted these results.

\section{Findings}

The findings in terms of the research hypotheses are discussed in this section.

\section{Verifying the First Hypothesis}

The first hypothesis states that "There is a statistically significant difference at the 0.01 level between the mean scores of the research participants of the experimental and control groups on the post administration of the overall EFL vocabulary test in favor of the experimental group". By applying t-test to compare the mean scores of the participants of two independent and homogeneous groups (experimental and control) in the post administration of the overall EFL vocabulary test and determining the statistical significance of the difference between them, the results were as shown in table (5):

Table (5): The research participants' mean scores, standard deviation, $t$-value and level of significance on the post administration of the overall EFL Vocabulary Test

\begin{tabular}{llllllll}
\hline Group & No & Mean & S. D & D. F & t-value & Sig & Level of sig. \\
Control & 30 & 22.4 & 3.02 & 58 & & & \\
Experimental & 30 & 29.2 & 3.93 & 58 & 7.51 & sig. & 0.01 \\
\hline
\end{tabular}

* The tabular value of $t$-test at the level of $(0.01)$ and $58 \mathrm{D}$.F is (2.66).

In light of the results of the previous table, it is clear that the calculated t-value of is 7.51, exceeding its tabular value of 2.66 at a degree of freedom 58 at (0.01) level of significance. Consequently, the first hypothesis of the research was confirmed. The results of the first hypothesis are consistent with results of previous studies, which are concerned with the development of EFL Vocabulary Learning, and among those studies are the studies of Radwan (2016); Salama (2016); Emam (2019); Emara (2019). 


\section{Verifying the first sub-hypothesis}

The following sub-hypothesis is derived from the first hypothesis. Regarding the first sub-hypothesis which states that "There is a statistically significant difference at the 0.01 level between the mean scores of the research participants of the experimental and control groups in EFL vocabulary recognition aspect on the post administration of the EFL vocabulary learning test in favour of the experimental group", the following table shows the participants' mean scores, t-value, standard deviation, and level of significance of the experimental and control groups in EFL vocabulary recognition aspect on the post administration of the EFL vocabulary learning test.

Table (6): The research participants' mean scores, standard deviation, $t$-value and level of significance in EFL vocabulary recognition aspect on the post administration of the EFL Vocabulary Test

\begin{tabular}{llllllll}
\hline Group & No & Mean & S. D & D. F & t-value & Sig & Level of sig. \\
Control & 30 & 10.0 & 1.26 & & & & \\
Experimental & 30 & 11.9 & 1.49 & 58 & 5.33 & sig. & 0.01 \\
\hline
\end{tabular}

* The tabular value of $t$-test at the level of $(0.01)$ and $58 \mathrm{D} . \mathrm{F}$ is (2.66).

In the light of the previous table's results, it is clear that the calculated t-value of 5.33 , exceeding its tabular value of 2.66 at a degree of freedom 58 at (0.01) level of significance. These results indicate that there is a real difference between the mean scores of the research participants in the experimental and control groups in EFL vocabulary recognition aspect on the post administration of the EFL vocabulary learning test in favor of the experimental group. Accordingly, the first sub-hypothesis of the research was confirmed.

\section{Verifying the second sub-hypothesis}

Regarding the second sub-hypothesis which states that "There is a statistically significant difference at the 0.01 level between the mean scores of the research participants of the experimental and control groups in EFL vocabulary meaning/ comprehension on 
the post administration of the EFL vocabulary learning test in favor of the experimental group", the following table shows the participants' mean scores, t-value, standard deviation, and level of significance of the experimental and control groups in EFL vocabulary meaning/ comprehension aspect on the post administration of the EFL vocabulary learning test.

Table (7): The research participants' mean scores, standard deviation, $t$-value and level of significance in EFL vocabulary meaning/ comprehension aspect on the post administration of the EFL Vocabulary Test

\begin{tabular}{llllllll}
\hline Group & No & Mean & S. D & D. F & t-value & Sig & Level of sig. \\
Control & 30 & 9.7 & 1.51 & 58 & 5.82 & sig. & 0.01 \\
Experimental & 30 & 11.93 & 1.46 & 58 & & \\
\hline
\end{tabular}

* The tabular value of $t$-test at the level of $(0.01)$ and $58 \mathrm{D}$.F is (2.66).

In the light of the previous table's results, it is clear that the calculated t-value is 5.82 , exceeding its tabular value of 2.66 at a degree of freedom 58 at (0.01) level of significance. These results indicate that there is a real difference between the mean scores of the research participants in the experimental and control groups in EFL vocabulary meaning/comprehension aspect on the post administration of the EFL vocabulary learning test in favor of the experimental group. Accordingly, the second sub-hypothesis of the research was confirmed.

\section{Verifying the third sub-hypothesis}

Regarding the third sub-hypothesis which states that "There is a statistically significant difference at the 0.01 level between the mean scores of the research participants of the experimental and control groups in EFL vocabulary use aspect on the post administration of the EFL vocabulary test in favor of the experimental group", the following table shows the participants' mean scores, t-value, standard deviation, and level of significance of the experimental and control groups in EFL vocabulary use aspect on the post administration of the EFL vocabulary test. 
Table (8): The research participants' mean scores, standard deviation, t-value and level of significance in EFL vocabulary use aspect on the post administration of the EFL

Vocabulary Test

\begin{tabular}{llllllll}
\hline Group & No & Mean & S. D & D. F & t-value & Sig & Level of sig. \\
$\begin{array}{l}\text { Control } \\
\begin{array}{l}\text { Experiment } \\
\text { al }\end{array}\end{array}$ & 30 & 2.7 & 0.51 & & & & \\
\hline
\end{tabular}

* The tabular value of $t$-test at the level of $(0.01)$ and $58 \mathrm{D}$.F is $(2.66)$.

In the light of the previous table's results, it is clear that the calculated t-value is 6.81 , exceeding its tabular value of 2.66 at a degree of freedom 58 at (0.01) level of significance. These results indicate that there is a real difference between the mean scores of the research participants in the experimental and control groups in EFL vocabulary use aspect on the post administration of the EFL vocabulary test in favor of the experimental group. Accordingly, the third sub-hypothesis of the research was confirmed.

\section{Verifying the Second Hypothesis}

The second hypothesis states that "There is not a statistically significant difference at the 0.01 level between the mean scores of the experimental group on the post/delayedpost administration of the EFL vocabulary test". By applying t-test to compare the mean scores of the participants of the experimental group in the post/delayed-post administration of the overall EFL vocabulary test and its three aspects and determining the statistical significance of the difference between them, the results were as shown below:

Table (9): The research participants' mean scores, standard deviation, $t$-value and level of significance in the post/delayed-post administration of the overall EFL Vocabulary Test with its three aspects for the experimental group

\begin{tabular}{|c|c|c|c|c|c|c|c|}
\hline Aspects & Measurement & No & Mean & S. D & D. F & t-value & Level of sig. \\
\hline Recognition & $\begin{array}{l}\text { delayed-post } \\
\text { Post }\end{array}$ & $\begin{array}{l}30 \\
30\end{array}$ & $\begin{array}{l}12.03 \\
11.9\end{array}$ & $\begin{array}{l}1.40 \\
1.49\end{array}$ & 58 & 0.84 & $\begin{array}{l}\text { Not. Sig. at } \\
0.01 \text { level }\end{array}$ \\
\hline $\begin{array}{l}\text { Meaning/ } \\
\text { Comprehension }\end{array}$ & $\begin{array}{l}\text { delayed-post } \\
\text { Post }\end{array}$ & $\begin{array}{l}30 \\
30\end{array}$ & $\begin{array}{l}11.91 \\
11.93\end{array}$ & $\begin{array}{l}1.36 \\
1.46\end{array}$ & 58 & 0.07 & $\begin{array}{l}\text { Not. Sig. at } \\
0.01 \text { level }\end{array}$ \\
\hline Use & $\begin{array}{l}\text { delayed-post } \\
\text { Post }\end{array}$ & $\begin{array}{l}30 \\
30\end{array}$ & $\begin{array}{l}5.93 \\
5.37\end{array}$ & $\begin{array}{l}1.28 \\
1.65\end{array}$ & 58 & 1.59 & $\begin{array}{l}\text { Not. Sig. at } \\
0.01 \text { level }\end{array}$ \\
\hline Overall Test & $\begin{array}{l}\text { delayed-post } \\
\text { Post }\end{array}$ & $\begin{array}{l}30 \\
30\end{array}$ & $\begin{array}{l}29.9 \\
29.2\end{array}$ & $\begin{array}{l}3.26 \\
3.93 \\
\end{array}$ & 58 & 1.26 & $\begin{array}{l}\text { Not. Sig. at } \\
0.01 \text { level }\end{array}$ \\
\hline
\end{tabular}




\section{* The tabular value of t-test at the level of $(0.01)$ and $58 \mathrm{D} . \mathrm{F}$ is (2.02).}

In the light of the results of the previous table, it is clear that the calculated t-values are $(0.84,0.07,1.59,1.26)$, less than its tabular value of 2.02 at a degree of freedom 58 at (0.01) level of significance. These results indicate that there is not a difference between the mean scores of the research participants in the experimental group, in the post/ delayedpost administration of the overall EFL vocabulary test with its three aspects. Accordingly, the second hypothesis of the research was confirmed.

\section{Discussion of the Findings of the Research}

The findings of the first hypothesis revealed that there was a statistically significant difference at the 0.01 level between the mean scores of the research participants of the experimental and control groups on the post administration of the overall EFL vocabulary test in favor of the experimental group. As proved previously, the participants of the experimental group showed more progress in their EFL vocabulary test with its three levels (recognition- meaning/comprehension-use) in the post administration of the EFL vocabulary learning test than the participants of the control group. The research's findings demonstrated that the t-value was significant at 0.01 level. Such progress proved and supported the first hypothesis with its three sub-hypotheses statistically. This progress was related as evidenced to the administration of the gamification-based program.

Moreover, the findings of the second hypothesis revealed that there was not statistically significant difference at the 0.01 level between the mean scores of the experimental group on the post/delayed-post administration of the EFL vocabulary test. This result proved the second hypothesis statistically. It also confirmed that the administration of the gamification-based program affected positively on EFL vocabulary retention among kindergartners. 


\section{Recommendations}

The following recommendations are suggested based on the findings of the current research:

- Learners should be defined about the nature of gamification and its various applications and uses.

- The gamification-based program should be implemented in teaching EFL vocabulary learning for kindergartners.

- New approaches, strategies, or techniques in EFL vocabulary teaching should be given more consideration.

- Kindergartners should be engaged in an exciting learning environment free from anxiety and fear of error which enables them to enjoy and learn.

- Curriculum developers should integrate the gamification strategy in kindergartners' curricula.

- EFL instructors should encourage their students to make their own dictionaries including any new learned vocabularies.

- EFL instructors should integrate technology in their sessions.

- EFL instructors should use various educational aids to help students in English vocabulary retention.

\section{Suggestions for Further Researches}

Several ideas came to the researcher's mind during the course of this research. These ideas were outside of the scope of this thesis. The researcher believes that these ideas can be areas for further researches in the future as follows:

1. An investigation of the effectiveness of using a gamification-based program on developing listening skill.

2. An investigation of the effectiveness of using a gamification-based program on developing speaking skill.

3. An investigation of the effectiveness of using a gamification-based program on developing reading skill. 
4. An investigation of the effectiveness of using a gamification-based program on developing writing skill.

5. The effect of gamification approach on critical and creative thinking.

6. A replication of the current study with students from different backgrounds and populations.

\section{References}

AlNatour, A. S., \& Hijazi, D. (2018). The impact of using electronic games on teaching English vocabulary for kindergarten students. US-China Foreign Language, 16(4), 193-205.

Beck, I. L., McKeown, M. G., \& Kucan, L. (2008). Creating robust vocabulary: Frequently asked questions and extended examples (Vol. 10). Guilford Press.

Bromley, K. (2002). Stretching Students' Vocabulary: Best Practices for Building the Rich Vocabulary Students Need to Achieve in Reading, Writing, and the Content Areas. Scholastic Inc.

Bunchball, I. (2010). Gamification 101: An introduction to the use of game dynamics to influence behavior. White paper, 9.

Cedeño, C., \& Santos, L. (2021). Chants in EFL Vocabulary Instruction with Young Learners: Potential, Composition and Application. Journal of English Language Teaching and Linguistics, 6(1), 153-165.

Deterding, S., Dixon, D., Khaled, R., \& Nacke, L. (2011, September). From game design elements to gamefulness: defining" gamification". In Proceedings of the 15th international academic MindTrek conference: Envisioning future media environments (pp. 9-15).

Emam, R. A. H. H. (2019). Integrating the Incidental and Intentional Learning for Developing EFL Vocabulary Learning and Social Skills among Official Language Preparatory School Pupils. Journal of the College of Education. Banha, 31 (January 4), 25-54.

Emara, A. A. M. (2019). The effectiveness of a proposed program based on Montessori in developing kindergartners' vocabulary acquisition and attitude 
towards English language learning.Unpublished M A Thesis, Facultyof Education, Damietta University, Egypt.

Flores, J. F. F. (2015). Using gamification to enhance second language learning. Digital Education Review, (27), 32-54.

Hanson, S., \& Padua, J. F. (2011). Teaching vocabulary explicitly. Honolulu: Pacific Resources for Education and Learning.

Henderson, L. M., van Rijn, E., James, E., Walker, S., Knowland, V. C., \&Gaskell, M. G. (2021). Timing storytime to maximize children's ability to retain new vocabulary. Journal of Experimental Child Psychology, 210, 105207.

Jalongo, M. R., \& Sobolak, M. J. (2011). Supporting young children's vocabulary growth: The challenges, the benefits, and evidence-based strategies. Early childhood education journal, 38(6), 421-429.

Kapp, K. M. (2012). The gamification of learning and instruction: game-based methods and strategies for training and education. John Wiley \& Sons.

Kara, K., \& Eveyik-Aydın, E. (2019). Effects of TPRS on very young learners' vocabulary acquisition. Advances in Language and Literary Studies, 10(1), 135146.

Kelley, E. S., Barker, R. M., Peters-Sanders, L., Madsen, K., Seven, Y., Soto, X., Olsen\& Goldstein, H. (2020). Feasible implementation strategies for improving vocabulary knowledge of high-risk preschoolers: Results from a clusterrandomized trial. Journal of Speech, Language, and Hearing Research, 63(12), 4000-4017.

Kim, S., Song, K., Lockee, B., \& Burton, J. (2018). What is gamification in learning and education?. In Gamification in learning and education (pp. 25-38). Springer, Cham.

Lee, J. J., \& Hammer, J. (2011). Gamification in education: What, how, why bother?. Academic exchange quarterly, 15(2), 146.

Lui, S. (2014). Use of gamification in vocabulary learning: A case study in Macau. In 4th CELC Symposium Proceedings (pp. 90-97). 
McKeown, M. G. (1993). Creating effective definitions for young word learners. Reading Research Quarterly, 17-31.

Neuman, S. B., \& Dwyer, J. (2009). Missing in action: Vocabulary instruction in pre-K. The reading teacher, 62(5), 384-392.

Nicholson, S. (2012, October). Strategies for meaningful gamification: Concepts behind transformative play and participatory museums. Presented at Meaningful Play 2012. Lansing, Michigan. Retrieved from:

http://scottnicholson.com/pubs/meaningfulstrategies.pdf

Pavlus, J. (2010) The Game of Life.Scientific American, 303, 4344. Retrieved from:https://doi.org/10.1038/scientificamerican1210-43

Radwan, E. M. K. (2016). Using an educational strategy based on pictorial reading for enhancing English vocabulary learning among primary stage pupils. Unpublished M A Thesis, Faculty of Graduate Studies for Education. Cairo University. Egypt.

Ramezanali, N. (2017). Short and long-term vocabulary learning and retention through multimedia glossing: A mixed methods research.

Ryder, R. J., \& Graves, M. F. (1994). Vocabulary instruction presented prior to reading in two basal readers. The Elementary School Journal, 95(2), 139-153.

Salama, H. A. (2016). Using some Brain-Compatible Teaching Strategies to Enhance Vocabulary Learning for Preparatory School Pupils. Unpublished M A Thesis, Faculty of Education, Mansoura University, Egypt.

Stahl, S. A., \& Fairbanks, M. M. (1986). The effects of vocabulary instruction: A model-based meta-analysis. Review of educational research, 56(1), 72-110.

Tozcu, A., \& Coady, J. (2004). Successful learning of frequent vocabulary through CALL also benefits reading comprehension and speed. Computer assisted language learning, 17(5), 473-495.

Watts. S. (1995). Vocabulary instruction during reading lessons in six classrooms. Journal of Reading Behavior, 27(3), 399-424.

Werbach, K., \& Hunter, D. (2012). For the win: How game thinking 
canrevolutionize your business. Philadelphia, PA: Wharton Digital Press.

Wright, T. S., \& Neuman, S. B. (2013). Vocabulary instruction in commonly used kindergarten core reading curricula. The Elementary School Journal, 113(3), 386408.

Zhou, W., \& Li, G. (2017). The effects of shared singing picture book instruction on Chinese immersion kindergarteners' spoken vocabulary recall and retention. Frontiers of Education in China, 12(1), 29-51. 